\title{
Fuzzy Topsis untuk Meningkatkan Akurasi dan Objektivitas Bobot pada Seleksi Vendor PT. Telkomsel TTC BSD
}

\author{
Abi Tulkhah ${ }^{1}$ dan Aries Saifudin ${ }^{2}$ \\ ${ }^{1,2}$ Teknik Informatika, Universitas Pamulang, Tangerang Selatan, Indonesia \\ e-mail: ${ }^{1,2}\{$ abimeiku, aries.saifudin\}@gmail.com
}

\begin{abstract}
Selection of vendors in PT. Telkomsel TTC (Telkomsel Telecommunication Center) BSD has some shortcomings that their maintenance costs in excess of the targeted system, and the processing time exceeds the specified time limit. The TOPSIS method can be applied to solve the problem by selecting the alternatives which have the shortest euclidian distance from the positive ideal solution. Ranking and weighting of criteria useful for determining solutions in the TOPSIS method. However, in many circumstances, sometimes the data obtained is inadequate and causes it cannot predict preference values correctly. Fuzzy logic can be used to help determine preference values in a structured manner. Fuzzy theory can be used to measure the concept of uncertainty more objectively than humans. In this study, the application of fuzzy TOPSIS method used to select the best vendors in PT. Telkomsel TTC BSD. The results of the research are the TOPSIS method is better than Fuzzy TOPSIS method.
\end{abstract}

Keywords: Fuzzy, TOPSIS, Weight, Selection, Vendor

\section{Pendahuluan}

TTC (Telkomsel Telecommunication Center) merupakan tempat yang menjadi pusat telekomunikasi, di dalam TTC terdapat proses pengolahan informasi dan gelombang sinyal untuk bisa memancarkan informasi dari satu TTC ke TTC yang lain di Indonesia atau dari TTC ke penyedia informasi melalui saluran telekomunikasi. Di dalam TTC terdapat perangkat hardware dan software untuk mengolah informasi. Kualitas hardware dan software akan menentukan kualitas dari layanan Telkomsel sebagai penyedia jasa telekomunikasi terhadap masyarakat luas. Untuk itu kualitas vendor dan pemilihan vendor menjadi faktor utama, karena semua hardware, software, instalasi serta maintenance bersumber dari vendor. Vendor adalah perusahaan yang menyediakan hardware, software, instalasi dan maintenance produk yang dijual kepada konsumen. Saat ini pemilihan vendor di Telkomsel menggunakan metode hitung rata-rata dan belum menggunakan metode pemeringkatan untuk mendukung pengambilan keputusan yang mengandung multikriteria. Hasil dari metode yang digunakan saat ini tidak sesuai dengan kriteria yang diberikan oleh PT. Telkomsel, yaitu terjadinya penambahan biaya maintenance software dan waktu pengerjaan melebihi target yang ditentukan.

Banyak metode yang digunakan dalam pemeringkatan dan pemilihan alternatif solusi untuk memecahkan permasalahan dalam pengambilan keputusan yang dipengaruhi oleh multikriteria. Salah satu metode yang dapat digunakan adalah TOPSIS (Technique for Order Performance by Similarity to Ideal Solution), pertama dikenalkan oleh Hwang dan Yoon pada tahun 1981 (Hwang \& Yoon, 1981). Prinsip utama metode TOPSIS adalah memilih alternatif yang mempunyai jarak euclidian paling dekat dengan solusi ideal positif dan paling jauh dari solusi ideal negatif (Tzeng \& Huang, 2011). Dalam memilih solusi, metode TOPSIS menggunakan bobot kriteria dan pemeringkatan. Data yang terkumpul/tersedia kadang tidak memadai untuk menentukan solusi dari permasalahan di kehidupan nyata. Selain itu, penilaian manusia sering memberikan preferensi yang kabur/kurang jelas dan tidak dapat memberikan nilai numerik yang tepat (J.-J. Wang, Jing, Zhang, \& Zhao, 2009). Agara penentuan preferensi lebih terstruktur dapat diterapkan logika fuzzy. Teori fuzzy dapat digunakan untuk membantu menilai sesuatu yang mengandung ketidakjelasan karena adanya subyektifitas manusia (Zadeh, 1965). Dalam hal ini, fuzzy mampu membantu untuk memperbaiki penentuan pemilihan bobot kriteria menggunakan Triangular Fuzzy Number (TFN) (Peng, Junwen, \& $\mathrm{Lu}, 2008$ ) untuk mengatasi kegagalan pemilihan bobot yang bersifat subjektif yang terjadi pada 
metode TOPSIS (Pochampally, Gupta, \& Kamarthi, 2004).

Untuk memperjelas penggunaan Fuzzy pada metode TOPSIS, pada penelitian ini akan melakukan seleksi vendor dengan menerapkan logika Fuzzy pada metode TOPSIS untuk meningkatkan akurasi dan objektivitas pada bobot kriteria, kemudian hasilnya akan dibandingkan dengan metode TOPSIS dan metode yang selama ini digunakan oleh PT. Telkomsel TTC BSD.

\section{Penelitian Terkait}

Dalam melakukan penelitian penerapan logika fuzzy pada metode TOPSIS perlu dilakukan review terhadap penelitian terkait. Review yang dilakukan bertujuan untuk mengetahui kendala yang ada dan hasil yang telah dicapai oleh peneliti lain. Dengan melakukan review, maka dapat memperoleh alternatif metode-metode yang dapat digunakan untuk menyelesaikan masalah.

Penelitian yang dilakukan oleh Ashrafzadeh, Rafiei, Isfahani, dan Zare (Ashrafzadeh, Rafiei, Isfahani, \& Zare, 2012) menyatakan bahwa pemilihan lokasi gudang adalah masalah keputusan multikriteria termasuk kedua kriteria kuantitatif dan kualitatif dan memiliki kepentingan strategis bagi banyak pendekatan companies. Konvensional ke lokasi gudang masalah pemilihan cenderung kurang efektif dalam menangani sifat tidak tepat atau samar dari penilaian linguistik. Di bawah banyak situasi, nilai-nilai kriteria kualitatif sering imprecisely didefinisikan untuk pengambil keputusan. Untuk mengatasi kesulitan ini, Fuzzy Multi Criteria Decision Making mampu memberi nilai pada pengambilan keputusan yang diusulkan. Dalam tulisan ini, kami menyajikan Multi Criteria Decision Making untuk memilih lokasi gudang bawah parsial atau informasi tidak lengkap (ketidakpastian). Pendekatan yang diusulkan terdiri dari dua langkah. Pada langkah 1, kita mengidentifikasi kriteria pemilihan lokasi gudang. Pada langkah 2, ahli memberikan peringkat linguistik dengan alternatif potensial terhadap kriteria yang dipilih. Fuzzy TOPSIS digunakan untuk menghasilkan pemilihan skor agregat alternatif terbaik. Makalah ini menunjukkan keberhasilan penerapan Fuzzy TOPSIS ke gudang nyata untuk masalah pemilihan lokasi dari perusahaan besar di Iran.

Penelitian yang dilakukan oleh Gao, Feng dan Yang (Peng et al., 2008) menyatakan bahwa pemilihan proyek sistem adalah pengambilan keputusan dengan masalah multikriteria (MCDM). Karya ini mengembangkan Pendekatan Fuzzy berdasarkan TOPSIS (Technique for Order Performance by Similarity to Ideal Solution), untuk memilih sistem informasi yang optimal dalam lingkungan kabur mana data sering tidak lengkap atau tidak begitu deterministik. Dalam tulisan ini, berat pentingnya setiap kriteria dan peringkat dari masing-masing alternatif dijelaskan dalam ketentuan linguistik dan dinyatakan dalam bilangan fuzzy segitiga. Dengan menggabungkan pendapat individu, jarak setiap alternatif dari fuzzy solusi ideal positif dengan solusi ideal negatif adalah menghitung masing-masing dengan metode titik. Kemudian, kedekatan koefisien diperoleh untuk peringkat urutan semua alternatif. Akhirnya, nyata kasus menunjukkan kelayakan dan efektivitas yang diusulkan metode.

Penelitian yang dilakukan oleh Singh dan Benyoucef (Singh \& Benyoucef, 2011) menyajikan suatu metodologi untuk memecahkan tawaran tertutup, multi-atribut membalikkan masalah lelang e-sourcing di mana item penjualan didefinisikan oleh beberapa atribut, pembeli lelang dan pemasok adalah penawar. Hanya ada satu pembeli dan sejumlah pemasok. Atribut kualitatif dan kuantitatif dari manfaat dan biaya jenis dipertimbangkan untuk memecahkan penentuan pemenang (WD) masalah pelelangan terbalik. Di sini, masalah WD dianggap sebagai masalah multikriteria pengambilan keputusan (MCDM). Dalam rangka untuk mengatasi ketidaktepatan pemasok atau pengambil keputusan dalam merumuskan nilai preferensi berbagai atribut di MCDM, metodologi berdasarkan Fuzzy TOPSIS bersama dengan mekanisme penentuan nilai linguistik fuzzy setiap atribut diusulkan dalam artikel ini. Metode entropi digunakan untuk menghitung bobot dari berbagai atribut secara otomatis tanpa keterlibatan para pengambil keputusan. Sebuah contoh ilustratif disajikan untuk menunjukkan penerapan metodologi yang diusulkan.

Penelitian yang dilakukan oleh Wang dan Lee (T.-C. Wang \& Lee, 2009) menyebutkan bahwa beberapa kriteria pengambilan keputusan (MCDM) secara luas digunakan dalam peringkat satu atau lebih alternatif dari satu set alternatif yang tersedia sehubungan dengan beberapa kriteria. Terinspirasi oleh MCDM sistematis mengevaluasi alternatif dalam berbagai kriteria, kami mengusulkan Fuzzy TOPSIS baru untuk mengevaluasi alternatif dengan mengintegrasikan menggunakan bobot subjektif dan objektif. Kebanyakan pendekatan MCDM mempertimbangkan bobot subjektif hanya pembuat keputusan. Namun, sikap pengguna akhir dapat menjadi faktor kunci. Kami mengusulkan 
pendekatan baru yang melibatkan pengguna akhir dalam seluruh proses pengambilan keputusan. Dalam pendekatan yang diusulkan ini, subjektifb obot ditugaskan oleh pengambil keputusan (DM) yang dinormalisasi menjadi skala yang sebanding. Selain itu, kami juga mengadopsi penilaian pengguna akhir sebagai berat obyektif berdasarkan teori entropi Shannon. Sebuah koefisien kedekatan didefinisikan untuk menentukan urutan peringkat alternatif dengan menghitung jarak ke kedua solusi ideal dan negatif-ideal. Sebuah studi kasus yang dilakukan menunjukkan bagaimana mengusulkan metode dapat digunakan untuk masalah perangkat lunak outsourcing. Dengan metode kami, kami menyediakan pembuat keputusan informasi lebih lanjut membuat keputusan yang lebih halus.

Penelitian yang dilakukan Lima Junior, Osiro, dan Carpinetti (Lima Junior, Osiro, \& Carpinetti, 2014) menyebutkan bahwa Pemilihan supplier telah menjadi aktivitas yang sangat penting untuk kinerja organisasi dan pemasok bahan baku. Studi yang disajikan dalam literatur mengusulkan penggunaan metode TOPSIS Fuzzy dan Fuzzy AHP (Fuzzy Analytic Hierarchy Process) untuk membantu proses pengambilan keputusan pemilihan supplier. Namun, tidak ada studi banding dua metode bila diterapkan pada masalah pemilihan supplier. Dengan demikian, makalah ini menyajikan analisis komparatif dari dua metode ini dalam konteks pemilihan supplier pengambilan keputusan. Perbandinga dibuat berdasarkan faktor: kecukupan perubahan alternatif atau kriteria; ketangkasan dalam proses pengambilan keputusan, kompleksitas komputasi; kecukupan untuk mendukung pengambilan keputusan kelompok; jumlah alternatif sup-tang dan kriteria; dan pemodelan ketidakpastian. Sebagai contoh ilustrasi, kedua metode yang digunakan untuk pemilihan pemasok dari perusahaan dalam rantai produksi otomotif. Selain itu, pengujian penghitungan dilakukan mengingat beberapa skenario pemilihan supplier. Hasil penelitian menunjukkan kedua metode cocok untuk masalah pemilihan supplier, terutama untuk mendukung pengambilan keputusan kelompok dan pemodelan ketidakpastian. Namun, analisis komparatif menunjukkan bahwa metode TOPSIS Fuzzy lebih cocok untuk masalah pemilihan supplier dalam hal perubahan alternatif dan kriteria, kelincahan dan sejumlah kriteria dan pemasok alternatif. Dengan demikian, studi banding ini membantu peneliti dan praktisi untuk memilih pendekatan yang lebih efektif untuk pemilihan supplier. Saran pekerjaan lebih lanjut juga diusulkan dengan menerapkan metode lain agar dapat memilih supplier dengan lebih baik.

Penelitian yang dilakukan oleh Soloukdar dan Parpanchi (Soloukdar \& Parpanchi, 2015) bertujuan untuk mengidentifikasi kriteria yang paling penting dan indikator dalam pemilihan vendor intelijen bisnis, dan peringkat vendor alatalat seperti menggunakan FAHP (Fuzzy Analytic Hierarchy Process) dan FTOPSIS (Fuzzy Technique for Order Performance by Similarity to Ideal Solution). Untuk mengetahui metode terbaik, maka dilakukan perbandingan hasil penerapan metode pada perusahaan NIOC (National Iranian Oil Company). Uji korelasi Spearman Rank digunakan untuk membandingkan metode dan menentukan korelasinya. Sebuah korelasi positif yang kuat diamati antara jajaran alat bisnis intelijen di tingkat signifikansi 0,05 di kedua metode. Hasil peringkat dengan cara FAHP metode menunjukkan bahwa IBM Perusahaan adalah yang terbaik, diikuti oleh Oracle, SAS, QlikTech, SAP dan Microsoft. Namun, berdasarkan metode TOPSIS, Oracle adalah perusahaan terkemuka, diikuti oleh IBM, SAS dan SAP dan akhirnya Microsoft.

Penelitian yang dilakukan oleh Kaya dan Kahraman (Kaya \& Kahraman, 2011) memaparkan tentang Perencanaan energi adalah masalah yang kompleks yang membutuhkan teknis, ekonomi, lingkungan dan sosial atribut memperhitungkan. Pemilihan teknologi energi terbaik memerlukan pertimbangan yang bertentangan kuantitatif dan kriteria evaluasi kualitatif. Ketika penilaian pembuat keputusan 'berada di bawah ketidakpastian, itu relatif sulit bagi mereka untuk memberikan nilai numerik yang tepat. Teori himpunan fuzzy adalah alat yang kuat yang dapat menangani ketidakpastian dalam hal informasi subjektif, tidak lengkap, dan jelas. Hal ini lebih mudah untuk seorang ahli perencanaan energi untuk membuat evaluasi dengan menggunakan istilah linguistik. Dalam tulisan ini, yang dimodifikasi Fuzzy Metodologi TOPSIS diusulkan untuk pemilihan alternatif terbaik teknologi energi. TOPSIS adalah multi kriteria pengambilan keputusan (MCDM) teknik yang menentukan alternatif terbaik dengan menghitung jarak dari solusi yang ideal positif dan negatif sesuai dengan nilai evaluasi ahli. Dalam metodologi yang diusulkan, bobot dari kriteria seleksi ditentukan oleh fuzzy berpasangan perbandingan matriks. Metodologi ini diterapkan untuk perencanaan energi pengambilan keputusan masalah. 


\section{Metodologi}

Metode yang saat ini digunakan sebagai metode terbaik untuk pemeringkatan yaitu metode TOPSIS. Metode TOPSIS merupakan metode yang dapat digunakan untuk membantu mengambil keputusan dengan melibatkan multikriteria dan banyak alternatif pilihan. Alternatif terbaik sebagai solusi merupakan alternatif yang memiliki jarak terdekat dari solusi ideal positif dan berjarak terjauh dari solusi ideal negatif.

TOPSIS mempertimbangkan kedua jarak tersebut karena alternatif yang dipilih tidak harus mempunyai jarak terbesar dari solusi ideal negatif dan memiliki jarak terdekat terhadap solusi ideal positif secara bersamaan. Jarak relatif suatu altenatif terhadap solusi ideal positif digunakan untuk menentukan solusi optimal pada metode TOPSIS. TOPSIS akan menghitung dan menentukan peringkat setiap alternatif sesuai nilai kedekatan relatif terhadap solusi ideal positif. Kemudian peringkat setiap alternatif dijadikan sebagai referensi untuk pengambilan keputusan dalam memilih alternatif terbaik sebagai solusi.

Adapun metode yang diusulkan pada penelitian ini yaitu metode Fuzzy TOPSIS. Fuzzy TOPSIS yang diusulkan dikembangkan dari metode TOPSIS (Technique for Order Performance by Similarity to Ideal Solution) dengan memberi bobot berupa nilai segitiga fuzzy (fuzzy triangular number) pada kriteria yang digunakan. Hal ini dikarenakan data yang tersedia kadang tidak memadai untuk memecakan masalah dalam kehidupan nyata karena penilaian manusia terhadap preferensi sering dipengaruhi subyektifitas, sehingga hasilnya kabur/kurang jelas dan tidak dapat menetukan nilai preferensi dengan nilai numerik yang tepat (J.-J. Wang et al., 2009) Sehingga dengan memberikan nilai bobot berupa nilai segitiga fuzzy (fuzzy triangular number) maka kriteria akan menjadi objektif (Pochampally et al., 2004).

Metode yang digunakan untuk menguji metode TOPSIS dan metode Fuzzy TOPSIS yaitu menggunakan metode Uji Akurasi. Metode Uji Akurasi merupakan metode yang mengukur kedekatan nilai hasil pengukuran dibandingkan nilai sebenarnya (true value atau reference value). Untuk menghitung akurasi diagnosis pada penelitian ini dilakukan dengan menghitung jumlah diagnosis menggunakan metode TOPSIS dan Fuzzy TOPSIS, kemudian dibagi dengan jumlah data.

\section{Hasil dan Pembahasan Penerapan Aplikasi}

Aplikasi yang dibuat memiliki tampilan seperti pada Gambar 1 dan Gambar 2. Gambar 1 adalah tampilan untuk menguji akurasi metode/model. Sedangkan Gambar 2 merupakan tampilan laporan hasil pengujian akurasi.

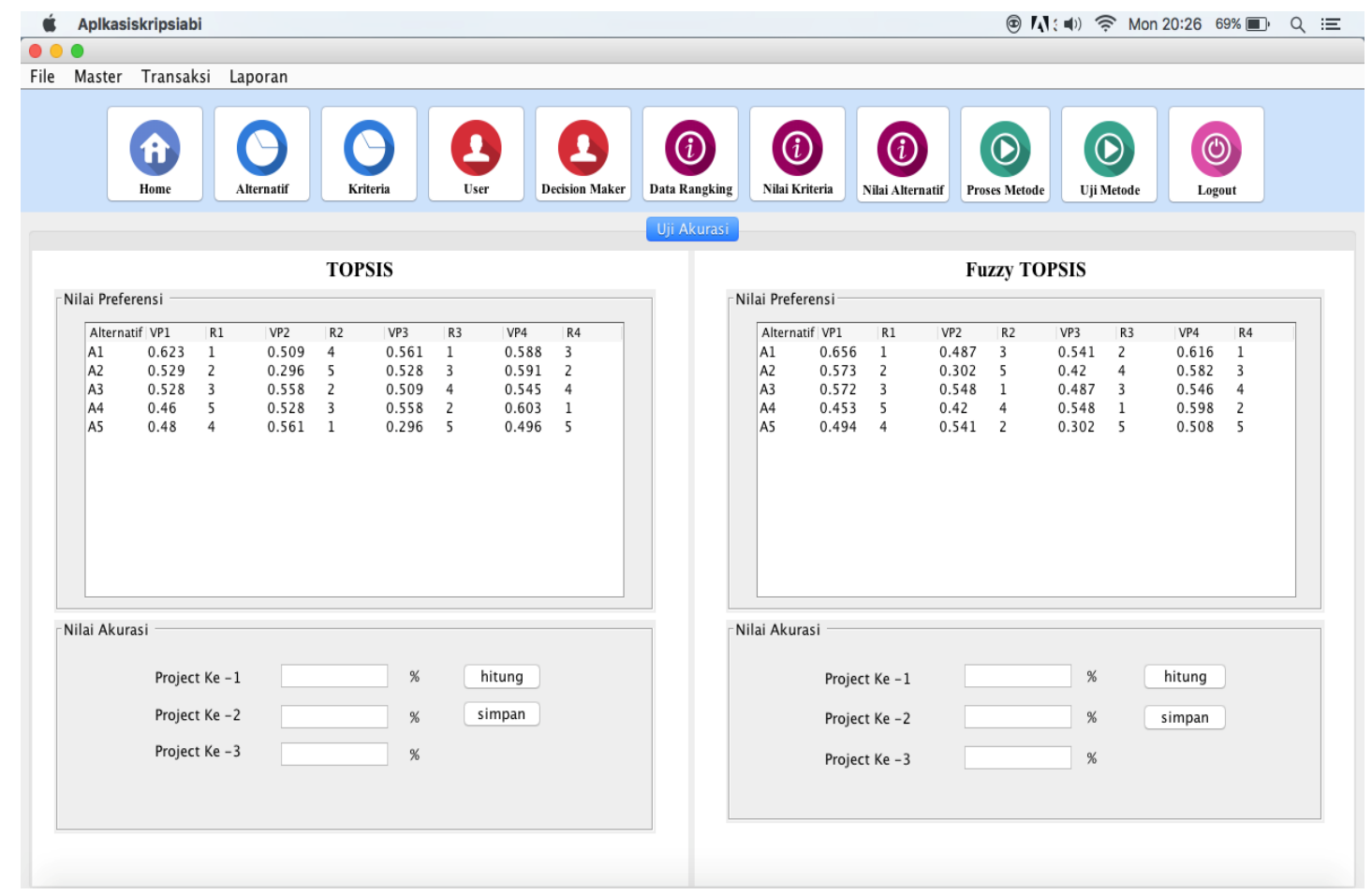

Gambar 1 Antarmuka Pengujian Akurasi Metode 


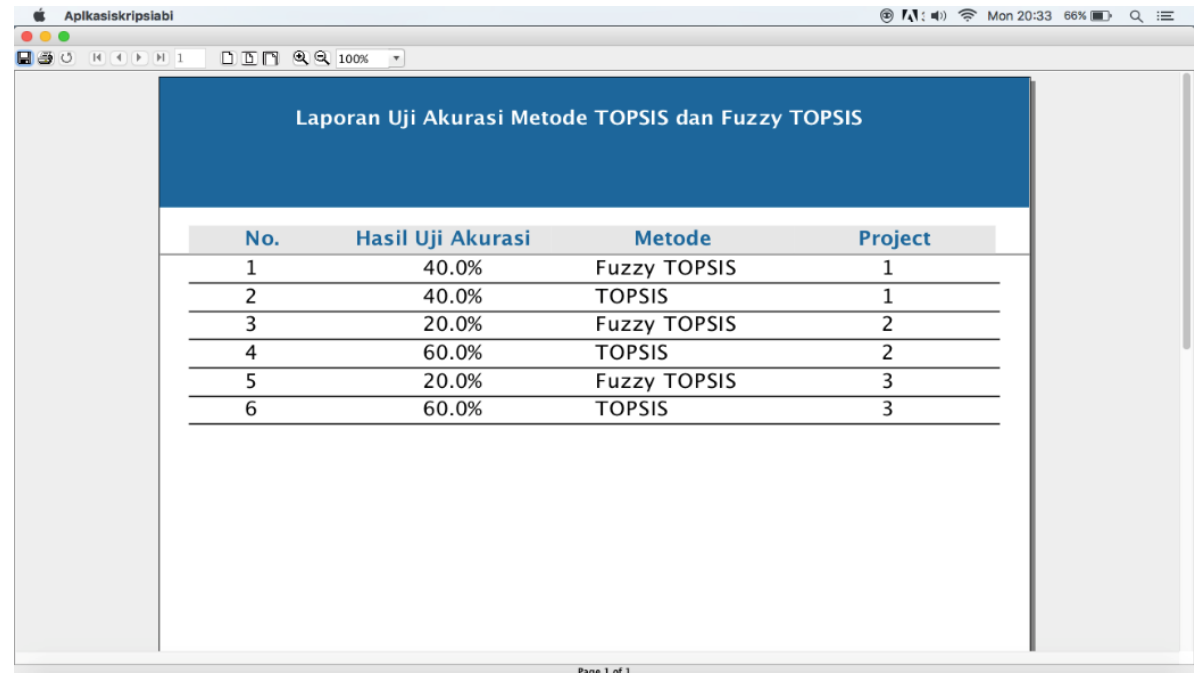

Gambar 2 Laporan Hasil Uji Akurasi

\section{Hasil}

Adapun hasil penghitungan yang diperoleh setelah dilakukan penelitian terhadap PT. Telkomsel TTC BSD untuk seleksi vendor terbaik menggunakan metode TOPSIS dan Fuzzy TOPSIS yang diimplementasikan ke dalam program yaitu sebagai berikut:

1. Seleksi Vendor dengan Metode TOPSIS.

Berdasarkan penghitungan yang dilakukan menggunakan sistem yang telah dibuat untuk seleksi vendor terbaik dengan metode TOPSIS yaitu sebagai berikut:

Tabel 1 Nilai dan Peringkat Vendor pada Project ke - 1 tahun 2015

\begin{tabular}{|c|c|c|c|}
\hline No. & Alternatif & Nilai Preferensi & Peringkat \\
\hline 1 & A1 & 0.638 & 1 \\
\hline 2 & A2 & 0.557 & 2 \\
\hline 3 & A3 & 0.499 & 4 \\
\hline 4 & A4 & 0.452 & 5 \\
\hline 5 & A5 & 0.505 & 3 \\
\hline
\end{tabular}

Tabel 2 Nilai dan Peringkat Vendor pada Project ke - 2 tahun 2015

\begin{tabular}{|c|c|c|c|}
\hline No. & Alternatif & Nilai Preferensi & Peringkat \\
\hline 1 & A1 & 0.495 & 4 \\
\hline 2 & A2 & 0.306 & 5 \\
\hline 3 & A3 & 0.562 & 2 \\
\hline 4 & A4 & 0.554 & 3 \\
\hline 5 & A5 & 0.575 & 1 \\
\hline
\end{tabular}

Tabel 3 Nilai dan Peringkat Vendor pada Project ke -3 tahun 2015

\begin{tabular}{|c|c|c|c|}
\hline No. & Alternatif & Nilai Preferensi & Peringkat \\
\hline 1 & A1 & 0.575 & 1 \\
\hline 2 & A2 & 0.554 & 3 \\
\hline 3 & A3 & 0.495 & 4 \\
\hline 4 & A4 & 0.562 & 2 \\
\hline 5 & A5 & 0.306 & 5 \\
\hline
\end{tabular}

Tabel 4 Nilai dan Peringkat Vendor pada Project ke -4 diprediksi

\begin{tabular}{|c|c|c|c|}
\hline No. & Alternatif & Nilai Preferensi & Peringkat \\
\hline 1 & A1 & 0.527 & 4 \\
\hline 2 & A2 & 0.651 & 1 \\
\hline 3 & A3 & 0.545 & 3 \\
\hline 4 & A4 & 0.567 & 2 \\
\hline 5 & A5 & 0.522 & 5 \\
\hline
\end{tabular}

2. Seleksi Vendor dengan Metode Fuzzy TOPSIS.

Berdasarkan penghitungan yang dilakukan menggunakan sistem yang telah dibuat untuk seleksi vendor terbaik dengan metode Fuzzy TOPSIS yaitu sebagai berikut:

Tabel 5 Nilai dan Peringkat Vendor pada Project ke-1 tahun 2015

\begin{tabular}{|c|c|c|c|}
\hline No. & Alternatif & Nilai Preferensi & Peringkat \\
\hline 1 & A1 & 0.312 & 5 \\
\hline 2 & A2 & 0.543 & 1 \\
\hline 3 & A3 & 0.506 & 3 \\
\hline 4 & A4 & 0.495 & 4 \\
\hline 5 & A5 & 0.515 & 2 \\
\hline
\end{tabular}


Tabel 6 Nilai dan Peringkat Vendor pada Project ke - 2 tahun 2015.

\begin{tabular}{|c|c|c|c|}
\hline No. & Alternatif & Nilai Preferensi & Peringkat \\
\hline 1 & A1 & 0.45 & 5 \\
\hline 2 & A2 & 0.533 & 1 \\
\hline 3 & A3 & 0.471 & 4 \\
\hline 4 & A4 & 0.491 & 2 \\
\hline 5 & A5 & 0.481 & 3 \\
\hline
\end{tabular}

Tabel 7 Nilai dan Peringkat Vendor pada Project ke -3 tahun 2015

\begin{tabular}{|c|c|c|c|}
\hline No. & Alternatif & Nilai Preferensi & Peringkat \\
\hline 1 & A1 & 0.481 & 3 \\
\hline 2 & A2 & 0.491 & 2 \\
\hline 3 & A3 & 0.45 & 5 \\
\hline 4 & A4 & 0.471 & 4 \\
\hline 5 & A5 & 0.533 & 1 \\
\hline
\end{tabular}

Tabel 8 Nilai dan Peringkat Vendor pada Project $\mathrm{ke}-4$ yang diprediksi

\begin{tabular}{|c|c|c|c|}
\hline No. & Alternatif & Nilai Preferensi & Peringkat \\
\hline 1 & A1 & 0.388 & 4 \\
\hline 2 & A2 & 0.386 & 5 \\
\hline 3 & A3 & 0.426 & 2 \\
\hline 4 & A4 & 0.401 & 3 \\
\hline 5 & A5 & 0.493 & 1 \\
\hline
\end{tabular}

3. Pengujian Metode TOPSIS dan Fuzzy TOPSIS dengan Uji Akurasi.

Berdasarkan nilai dan peringkat vendor yang diperoleh dengan menggunakan metode TOPSIS dan Fuzzy TOPSIS yaitu sebagai berikut:

Tabel 9 Hasil Uji Akurasi pada Metode TOPSIS dan Metode Fuzzy TOPSIS.

\begin{tabular}{|c|c|c|c|}
\hline \multirow{2}{*}{ No. } & \multirow{2}{*}{ Project } & \multicolumn{2}{|c|}{ Nilai Akurasi } \\
\cline { 3 - 4 } & & Topsis & Fuzzy \\
\hline 1 & 1 & $40 \%$ & $40 \%$ \\
\hline 2 & 2 & $60 \%$ & $20 \%$ \\
\hline 3 & 3 & $60 \%$ & $20 \%$ \\
\hline
\end{tabular}

\section{Pembahasan}

Pemberian bobot pada metode TOPSIS menggunakan peringkat kecocokan Sangat Tinggi untuk angka 5, Tinggi untuk angka 4, Sedang untuk angka 3, Rendah untuk angka 2, dan Sangat Rendah untuk angka 1 , kemudian untuk pemberian nilai pada alternatif menggunakan angka sesuai yang diperoleh dari PT. Telkomsel TTC BSD yaitu menggunakan skala angka dari $0-100$, pada metode Fuzzy TOPSIS, fuzzy digunakan untuk meningkatkan akurasi dan objektivitas pada bobot kriteria dan alternatif, penerapan metode fuzzy untuk meningkatkan akurasi pada metode topsis yaitu dengan memberikan nilai pada bobot kriteria dan bobot alternatif berupa bilangan segitiga fuzzy (triangular fuzzy number) dengan nilai 0-1. Adapun untuk meningkatkan objektivitas pada bobot yaitu memberikan nilai fuzzy berupa triangular fuzzy number dengan variabel linguistic Sangat Tinggi dengan nilai crisp 1, Tinggi dengan nilai crisp 0.75, Sedang dengan nilai crisp 0.5, Rendah dengan nilai crisp 0.25 dan Sangat Rendah dengan nilai crisp 0 . Nilai variabel diperoleh dari kuisioner yang diberikan kepada pembuat keputusan (decision maker) dari PT. Telkomsel TTC BSD, kemudian nilai dikonversi ke dalam nilai crisp kemudian dihitung untuk mendapatkan nilai rata-rata yang akan digunakan sebagai hasil pembobotan kriteria dan hasil pembobotan nilai alternatif dari 3 pembuat keputusan (decision maker). Adapun proses dari normalisasi matriks sampai dengan hasil peringkat (ranking) sama halnya langkah-langkah pada metode TOPSIS.

Setelah dilakukan penghitungan menggunakan program pada metode TOPSIS dan Fuzzy TOPSIS pada tabel 1 sampai dengan tabel 9 diperoleh hasil metode TOPSIS mempunyai nilai akurasi lebih tinggi dibandingkan dengan metode Fuzzy TOPSIS, hasil bahwa metode TOPSIS lebih akurat dan lebih baik daripada metode Fuzzy TOPSIS, dengan tingkat akurat metode TOPSIS $40 \%$ pada project ke- $1,60 \%$ pada project $\mathrm{ke}-2$ dan $60 \%$ pada project ke-3. Sedangkan tingkat akurasi untuk metode Fuzzy TOPSIS yaitu $40 \%$ pada project $\mathrm{ke}-1,20 \%$ pada project $\mathrm{ke}-2$ dan $20 \%$ pada project ke-3.

\section{Kesimpulan}

Penerapan metode Fuzzy pada metode TOPSIS yaitu dengan memberikan nilai terhadap bobot kriteria dan nilai pada alternatif berupa nilai linguistic yaitu Sangat Rendah, Rendah, Sedang, Tinggi, Sangat Tinggi. Kemudian segitiga bilangan fuzzy digunakan untuk menggambarkan 5 penilaian tersebut sehingga mendapatkan nilai crisp yang nantinya digunakan dalam proses pehitungan metode TOPSIS. Pemberian bobot lebih objektif karena pemberian bobot menggunakan nilai bilangan segitiga fuzzy (triangular fuzzy number) dengan memberikan nilai crisp pada masing-masing peringkat variabel linguistic. 
Berdasarkan hasil pengujian menggunakan metode uji akurasi pada 3 project sebelumnya pada tahun 2015 maka diperoleh hasil bahwa metode TOPSIS lebih akurat dan lebih baik daripada metode Fuzzy TOPSIS, dengan tingkat akurat metode TOPSIS $40 \%$ pada project $\mathrm{ke}-1,60 \%$ pada project $\mathrm{ke}-2$ dan $60 \%$ pada project ke-3. Sedangkan tingkat akurasi untuk metode Fuzzy TOPSIS yaitu $40 \%$ pada project $\mathrm{ke}-1,20 \%$ pada project $\mathrm{ke}-2$ dan $20 \%$ pada project $\mathrm{ke}-3$.

\section{Daftar Pustaka}

Ashrafzadeh, M., Rafiei, F. M., Isfahani, N. M., \& Zare, Z. (2012). Application of fuzzy TOPSIS method for the selection of Warehouse Location: A Case Study. Interdisciplinary J. of Contemporary Research in Business, 3, 655-671.

Hwang, C.-L., \& Yoon, K. (1981). Multiple Attribute Decision Making: Methods and Applications A State-of-the-Art Survey. Lecture Notes in Operations Research and Mathematical Economics Ch. Schneeweiß Invariant Imbeddlng. Proceedmgs VoL 58 P. B. Hagelschuer. TheOrie der linearen Dekomposition. VII. 191 Selten Growth Irl Open Economles. V. S. Ashour. Sequenclng Theory. V. Beh. Berlin, Heidelberg: Springer Berlin Heidelberg. https://doi.org/10.1007/978-3-642-48318-9

Kaya, T., \& Kahraman, C. (2011). Multicriteria Decision Making in Energy Planning Using a Modified Fuzzy TOPSIS Methodology. Expert Systems with Applications, 38(6), 6577-6585. https://doi.org/10.1016/j.eswa.2010.11.081

Lima Junior, F. R., Osiro, L., \& Carpinetti, L. C. R. (2014). A Comparison Between Fuzzy AHP and Fuzzy TOPSIS Methods to Supplier Selection. Applied Soft Computing Journal, 21, 194-209. https://doi.org/10.1016/j.asoc.2014.03.014

Peng, G., Junwen, F., \& Lu, Y. (2008). Fuzzy TOPSIS algorithm for multiple criteria decision making with an application in information systems project selection. 2008 International Conference on Wireless Communications, Networking and Mobile Computing, WiCOM 2008, 4-7. https://doi.org/10.1109/WiCom.2008.1759

Pochampally, K. K., Gupta, S. M., \& Kamarthi, S. V. (2004). Evaluation of Production Facilities in a Closed-loop Supply Chain: A Fuzzy TOPSIS Approach. In S. M. Gupta (Ed.), Environmentally Conscious Manufacturing III (Vol. 5262, pp. 125138). https://doi.org/10.1117/12.516172

Singh, R. K., \& Benyoucef, L. (2011). A fuzzy TOPSIS based approach for e-sourcing. Engineering Applications of Artificial Intelligence, 24(3), 437448. https://doi.org/10.1016/j.engappai.2010.09.006

Soloukdar, A., \& Parpanchi, S. A. (2015). Comparing Fuzzy AHP and Fuzzy TOPSIS for Evaluation of Business Intelligence Vendors. Decision Science Letters, 4(2), 137-164. https://doi.org/10.5267/j.dsl.2015.1.002

Tzeng, G.-H., \& Huang, J.-J. (2011). Multiple Attribute Decision Making: Methods and Applications. Florida: CRC Press. Retrieved from https://www.crcpress.com/Multiple-AttributeDecision-Making-Methods-andApplications/TzengHuang/p/book/9781439861578

Wang, J.-J., Jing, Y.-Y., Zhang, C.-F., \& Zhao, J.-H. (2009). Review on Multi-Criteria Decision Analysis Aid in Sustainable Energy DecisionMaking. Renewable and Sustainable Energy Reviews, 13(9), 2263-2278. https://doi.org/10.1016/j.rser.2009.06.021

Wang, T.-C., \& Lee, H.-D. (2009). Developing a fuzzy TOPSIS approach based on subjective weights and objective weights. Expert Systems with Applications, 36(5), 8980-8985. https://doi.org/10.1016/j.eswa.2008.11.035

Zadeh, L. A. (1965). Fuzzy sets. Information and Control, 8(3), 338-353. https://doi.org/10.1016/S0019-9958(65)90241-X 